\title{
A NUMERICAL OIL TRAJECTORY FORECAST MODEL USED TO ASSESS THE HAZARD TO LONG ISLAND BEACHES FROM OIL ENTERING THE NEW YORK BIGHT APEX FROM FEBRUARY 11-24, 1977
}

\author{
A.G. Tingle And D.A. Dieterle
}

March 1977

ATMOSPHERIC SCIENCES DIVISION

BROOKHAVEN NATIONAL LABORATORY ASSOCIATED UNIVERSITIES, INC.

UNDER CONTRACT NO. EY-76-C-02-0016 WITH THE

UNITED STATES ENERGY RESEARCH AND DEVELOPMENT ADMINISTRATION 


\section{DISCLAIMER}

This report was prepared as an account of work sponsored by an agency of the United States Government. Neither the United States Government nor any agency Thereof, nor any of their employees, makes any warranty, express or implied, or assumes any legal liability or responsibility for the accuracy, completeness, or usefulness of any information, apparatus, product, or process disclosed, or represents that its use would not infringe privately owned rights. Reference herein to any specific commercial product, process, or service by trade name, trademark, manufacturer, or otherwise does not necessarily constitute or imply its endorsement, recommendation, or favoring by the United States Government or any agency thereof. The views and opinions of authors expressed herein do not necessarily state or reflect those of the United States Government or any agency thereof. 


\section{DISCLAIMER}

Portions of this document may be illegible in electronic image products. Images are produced from the best available original document. 


\title{
A NUMERICAL OIL TRAJECTORY FORECAST MODEL USED TO ASSESS THE HAZARD TO LONG ISLAND BEACHES FROM OIL ENTERING THE NEW YORK BIGHT APEX FROM FEBRUARY 11-24, 1977
}

\author{
A.G. TINGLE AND D.A. DIETERLE
}

March 1977

Research sponsored by NOAA/MESA New York Bight Project, Stony Brook, New York 11794

and under Contract No. EY-76-C-02-0016 with the United States Energy Research and Development Administration.

ATMOSPHERIC SCIENCES DIVISION
DEPARTMENT OF APPLIED SCIENCE
DEN

BROOKHAVEN NATIONAL LABORATORY UPTON, NEW YORK 11973 
N O T I C E

I'his report was preparèd as ano account of work sponsored by the United Biales Government. Neither the United States nor the United States Energy Research and Development Administration, nor any of their employees, nor any of their contractors, subcontractors, or their employees, makes any warranty, express or implied, or assumes any legal liability or responsibility for the accuracy, completeness or usefulness of any information, apparatus, product or process disclosed, or represents that its use would not infringe privately owned rights.

Printed in the United States of America

Available from

National Technicial Infurmatiun Service

U.S. Department of Commerce

5285 Port Royal Road

Springfield, VA 22161

Price: Printed Copy $\$ 4.00$; Microfiche $\$ 3.00$

April 1977

400 copies 


\section{ABSTRACT}

Oil spilling into the Hudson River from a grounded barge (carrying 400,000 gallons) was observed entering the N. Y. Bight Apex on 11 February 1977. A computer model was used to forecast the subsequent trajectory of this oil and to assess the hazard to Long Island beaches. Oil was forecast to wash ashore on the 13 th on Rockaway or Long Beach, depending upon the initial position of the oil in the Bight. Oil was observed on Rockaway Beach on the 13th. Additional daily forecasts indicated no further hazard to Long Island, also in accordance with observations, and the forecasts were terminated on the $16 \mathrm{th}$. The model was also used to assess a beaching event that occurred a week later. The complete calculations are available on microfiche in graphics format. 


\section{CONTENTS}

I. Discussion of Problem

Page

1

TT . Model Description

III. Forecast Results and Accuracy Assessment

5

IV. The Beaching of $0 i 1$ on February 22, 1977

V.

The Microfiche Plots 


\section{Discussion of Problem}

On 11 February $1977 \mathrm{Mr}$. Bernard Manowitz of Brookhaven National Laboratory was informed by Charles Parker of the MESA N. Y. Bight Project that oil from a grounded barge in the Hudson River (carrying 400,000 gallons) could be entering the Bight Apex. Since the winds were southwest there was a strong potential that the oil would wash ashore somewhere along the southern Long Island beaches. Mr. Parker inquired whether the computer model previously used in an assessment of the beaching of floatables on Long Island in June 1976 could be adapted to provide daily forecasts of the potential hazard until MESA indicated that no further model runs were warranted.

Dwight Dieterle and Arthur Tingle agreed that the computer program could be modified to produce a "printout" forecast initially, followed by a more complete analysis using computer graphics. This meant that we could answer the following type of question: "If the oil is at some position, where is it forecast to be 24 hours later?" With the graphics, we could address such problems as variable release rates of the oil into the Apex, the relative importance of winds and currents in the transport, and readily identify a variety of hazardous situations.

Discussions between Charles Parker and Arthur Tingle resulted in the following approach to the problem. Oil was observed on the Rockaway side of the harbor, but it was not known where it might be in the Apex or at what rate it was entering the Apex. Therefore, nine simulated spills covering an area of about $150 \mathrm{~km}^{2}$ (see map In F1gure 1) were to be released each six hours and tracked until the end of the forecast period. By this means, the "correct" spill track could be used for the 


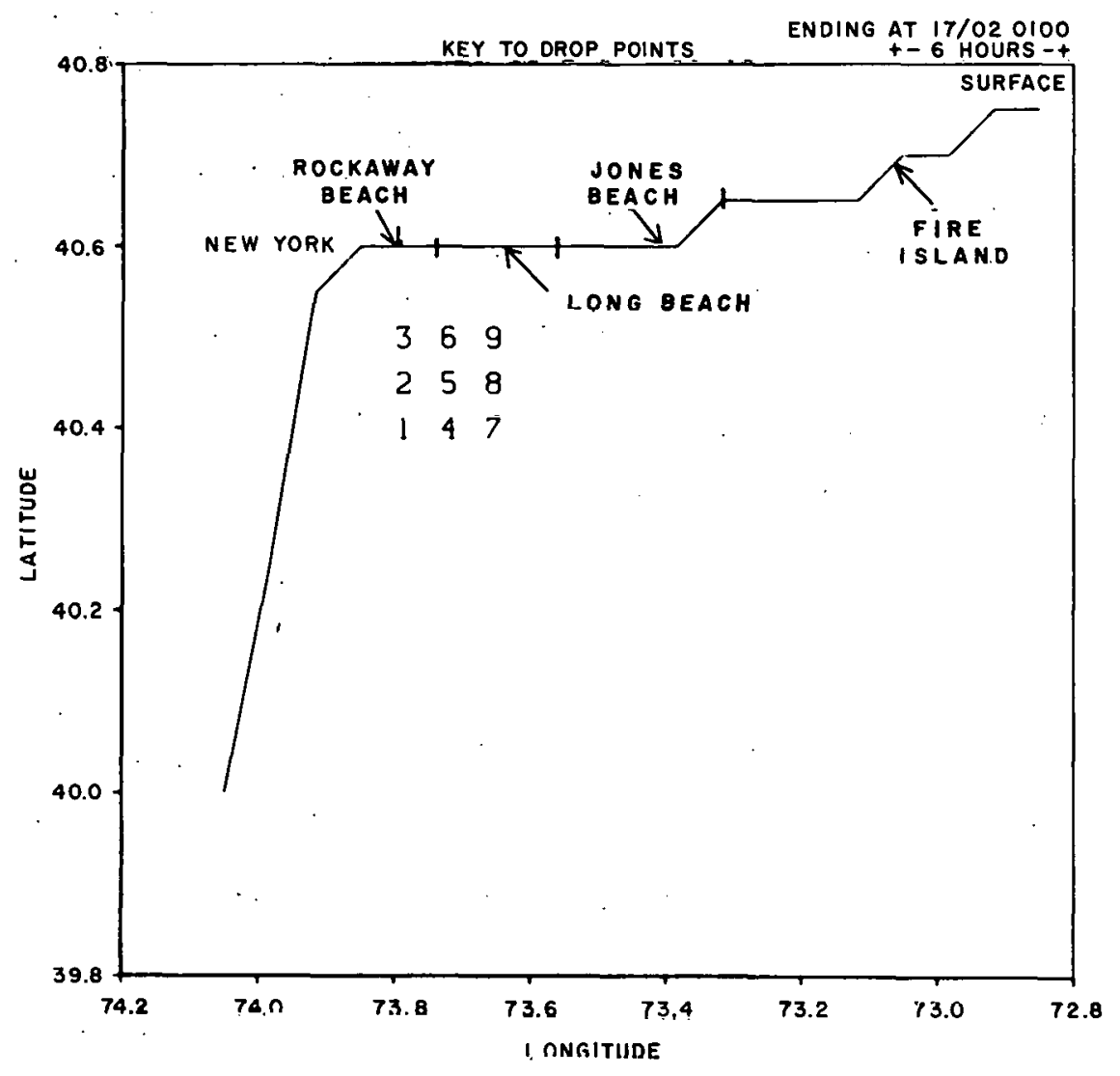

Figure 1. Release positions for the simulated oil spilis. Several positions were used with a new release from each every six hours since the actual oil location and release ratc in tho $\Lambda$ pex were not knnm. The separation is 5.67 $\mathrm{km}$. 
forecast after : a helicopter located the oil. Unfortunately, the helicopter was not used and the "nine spill" procedure was followed throughout the project. This meant that the forecast product was of the format: "If the oil is at Ambrose it will reach. Long Beach in tweleve hours; if it is $15 \mathrm{~km} \mathrm{SE}$ of Ambrose, then it should remain at sea."

The other inputs required for the model were the observed and forecast winds for Ambrose (which is in the Apex). These were obtained by telephone from the NOAA Weather Service Forecast Office in New York. The observed winds are recorded each three hours and kept for about three days. The forecast winds are for 42 hours at 6-hour intervals and are updated each 12 hours (using $00 Z$ and 122 meteorological data). However, the forecasts come over the teletype and are not available until about 9 hours after the observed data. Therefore, the agreed. forecast procedure was:

1) : Call WSFO in New York for the observed winds for the previous 24 hours and for the forecast winds. (about 1430 EST each day);

2) Run the model and interpret the results;

3) Cal1 MESA and discuss the results (about 1600 EST);

4) Plot the results on microfiche for later analysis.

\section{Mode1 Description}

The model consists of three major components

1) An Eulerian model that somputes, dynamically, the wind driven currents; 
2) A Lagrangian modei that computes both the trajectory of the surface slick and the trajectory of:material in the water column. This is a particle-in-cell diffusion model :if several hundred "particles" are released, depending on the spill rate;

3) Various graphic routines for presenting the results.

The current model (after Platiman, J. Phys. Oceanography, April 1972) is a one-layer free surface numerical model that responds to surface wind stress, bottom friction, the geostrophic pressure gradient, the Coriolis force, and the bottom topography. The model is applicable when the water column 1 s of constant density, a situation which exists during winter in the coastal region. The model does not compute tides or estuarine discharges. The grid spacing is 3 minutes in latitude and 4 minutes in longitude (about $5.67 \mathrm{~km}$ ).

In the trajectory model, oil was assumed to beach if a particle. representing it came within 3 kilometers of the shore, since the diameter of an oil spili can be several kilometers and the cffect of tides ani waves was not computed. The particles were not allowed to "stick" to the shore, but were allowed to move along shore or offshore depending upon the winds and currents. We also assumed that the surfacc oil moves as the vector sum of the current speed and $3 \%$ of the wind speed. There is controversy abour this assumption, but this is an input parameter to the computer program and could have been changed if observations were available. 
The model has been validated against drift card data taken by MESA. The results agreed as to time and distance from shore, the shore areas impacted, and the monthly statistics. The details are available from the authors. The computed alongshore currents are compared against observations taken by Brookhaven off the south shore of Long Island in February and March 1976 (Figure 2). Only one wind station was used to drive the model and this is not valid for fast moving storms, e.g., as shown for March 6 in Figures 2 and 3 . In this case, the model was computing $5 \mathrm{~cm} \mathrm{sec}^{-1}$ eastward flow compared with the observed $10 \mathrm{~cm} \mathrm{sec}^{-1}$ westward flow. We believe that this is mostly due to the complex geostrophic forces set up by the cold front. (Note that the storm on March 10 was modeled quite wel1.) The small high frequency observed peaks in Figure 2 are the diurnal tides. This means that we must model the wind field in computing the general shelf circulation and, of course, that the tides must be considered as the oil gets close to the beach. However, for the present problem the winds account for about two-thirds of the transport. The winds were taken at the spill site. so we can have reasonable confidence in the results. The comparison in Figure 2 also indicates that we can have reasonable confidence in the computed currents, usually within $10 \mathrm{~cm} \mathrm{sec}{ }^{-1}$, except for certain complex meteorological situations.

III. Forecast Results and Accuracy Assessment

Mr. Parker asked that we try to assess the accuracy of our forecasts in addition to presenting the results. The most important component of the forecast oil trajectory is the wind forecast. Two 24-hour wind 


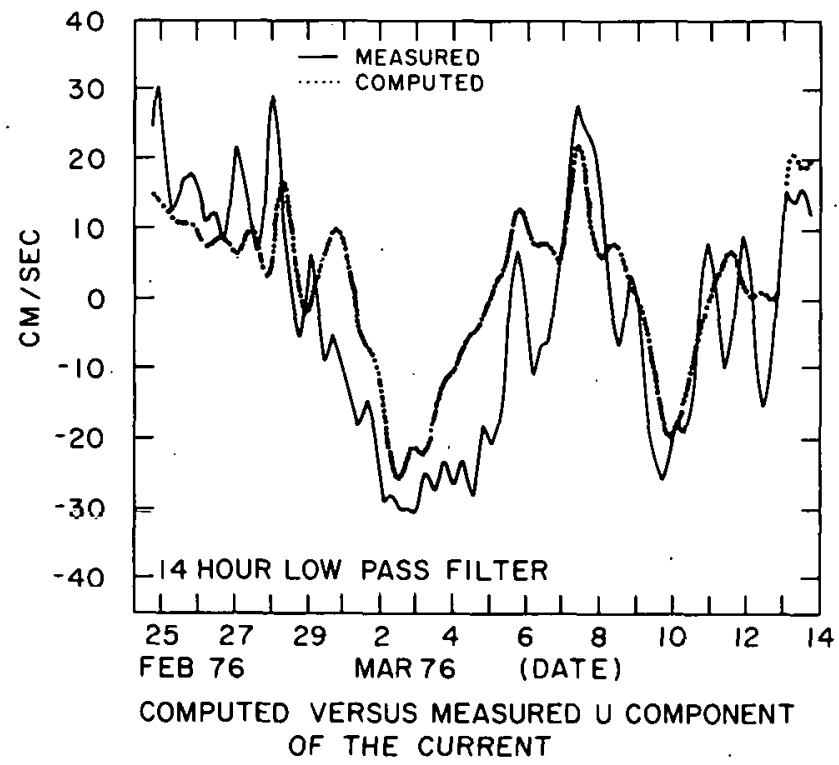

Figure 2. The computed (dotted line) currents versus the observed currents (taken by Brookhaven) at the SPAR buoy south of l'iana Beach. The dlscrepancy on March 6 is probably caused by the cold front shown in Figure 3 , as discussed in the text. The small observed peaks are the diurnal tides which were not flltered out of the observations. 


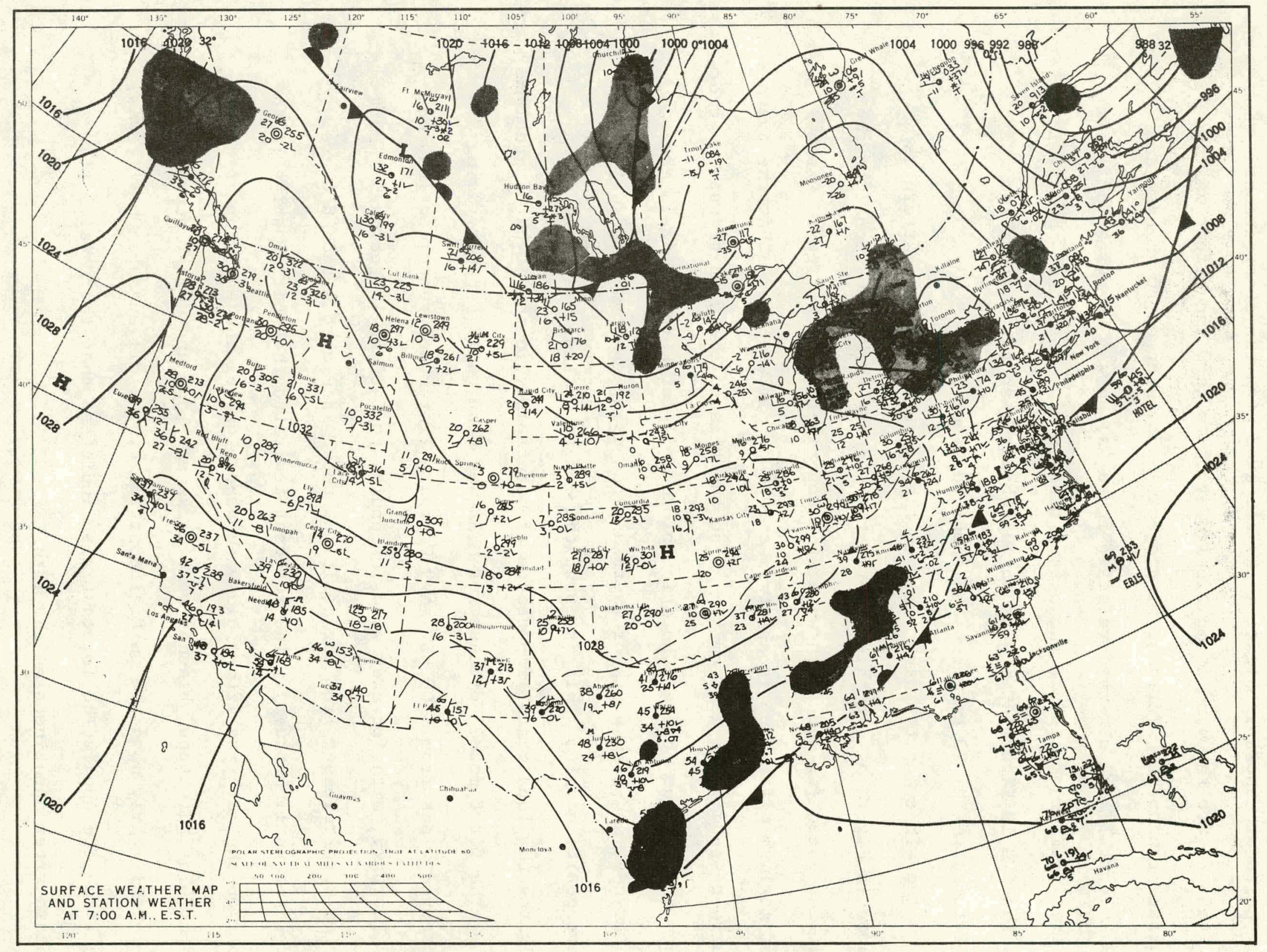

Fizure 3. The surface weather map for 0700 on March 6, 1976. This shows a complex wind field over the N.Y.

Bight. Only one wind station was used for the computations in Figure 2 and for the present oil spill problem. 
forecasts are shown in Figure 4 as compared with the observations. In this figure the wind is multiplied by $3 \%$ to show the effect on the surface transport. Forecast 非 1 projects a movement of $20 \mathrm{~km}$ east and $10 \mathrm{~km}$ north. The observed values (Figure $4 \mathrm{a}$ ) show $5 \mathrm{~km}$ north and $10 \mathrm{~km}$ east. Similar errors are shown for Forecast 非. Note that the origin of the PVD in Figure 4C starts on 13 February, so that we are showing a forecast $\Delta \mathrm{X}$ of $20 \mathrm{~km}$ versus an observed $\Delta \mathrm{X}$ of $10 \mathrm{~km}$.

The effect of the wind errur on the computed current pattern is shown in Figure 5. In this figure, the vectors are proportional to the current speed $\left(\mathrm{cm} \mathrm{sec}^{-1}\right)$ shown at the top right of each figure, where the maximum difference is about $13 \mathrm{~cm} \mathrm{sec}^{-1}$. If we assume that the average current speed error is $6 \mathrm{~cm} \mathrm{sec}^{-1}$ and add this to the wind transport error, then the 24-hour forecast position of the oil for Forecast 非 is about $15 \mathrm{~km}$ east and $5 \mathrm{~km}$ south of where a rerun using observed wind data would have positioned it. This is about the length of Long Beach and demonstrates the fundamental importance of meteorology in this type of problem.

The first model forecast for MESA was done on 12 February using observed winds from 1300 EST on 9 February (for model runup) to 1600 on 12 February, with forecast winds extending to 0400 on 14 February. Particles were released from the positions shown in Figure 1 each 6 hours starting on 11 February. The forecast indicated that oil floating in the Apex on the 11th and 12th could wash ashore during the early hours of the 13th. The threatened beaches were Rockaway, Long and Jones, depending very critically upon the initial position of the oil and upon how it was entering the Apex. The forecast also indicated that there was little hazard after about noon on the 13 th. 
(A)

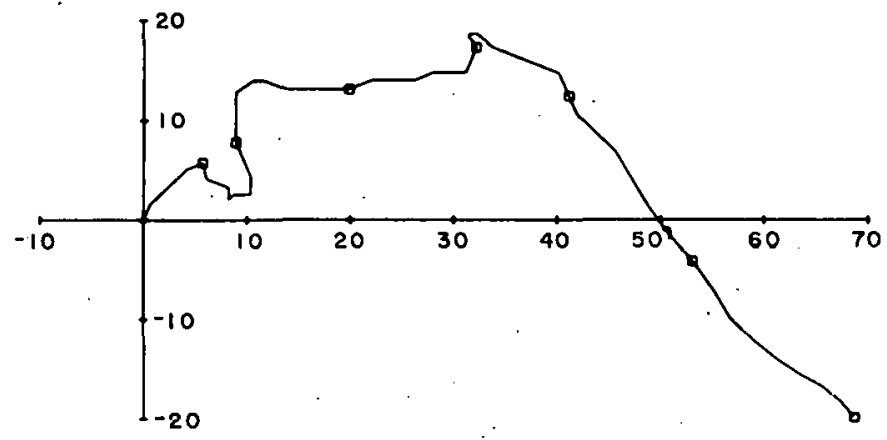

PVD (KM) OF TRANSPORT WINO II FEB 1600 - 18 FEB 0400

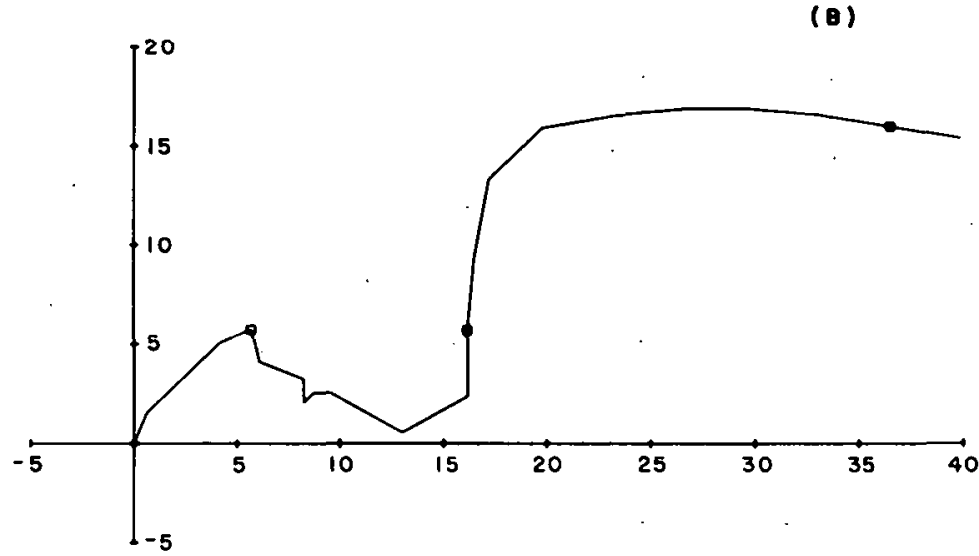

PVD (KM) OF TRANSPORT WIND IIFEB 1600- 14 FEB 0400

(c)

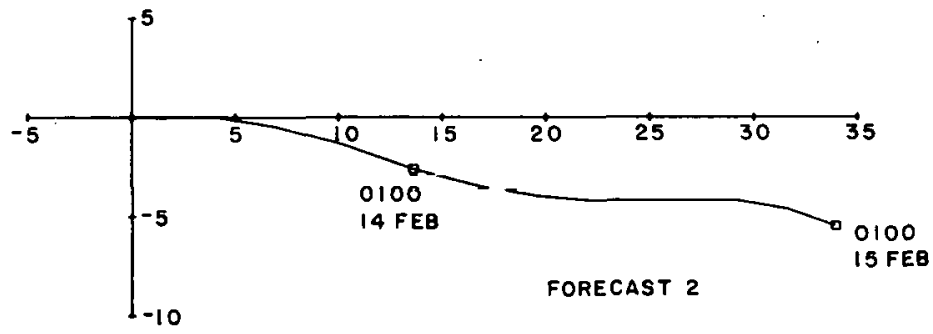

PVD (KM) OF TRANSPORT WINDI3 FEB 1300-15FEB OIOO

Figure 4. The observed Ambrosc winds (A), the winds used in the first forecast for MESA (B), and the winds used in the second forecast (C). The winds are plottcd as $3 \%$ of the wind PVD. The small squares mark 0100EST each day. The starting and ending time of each PVD are listed below each plot. 

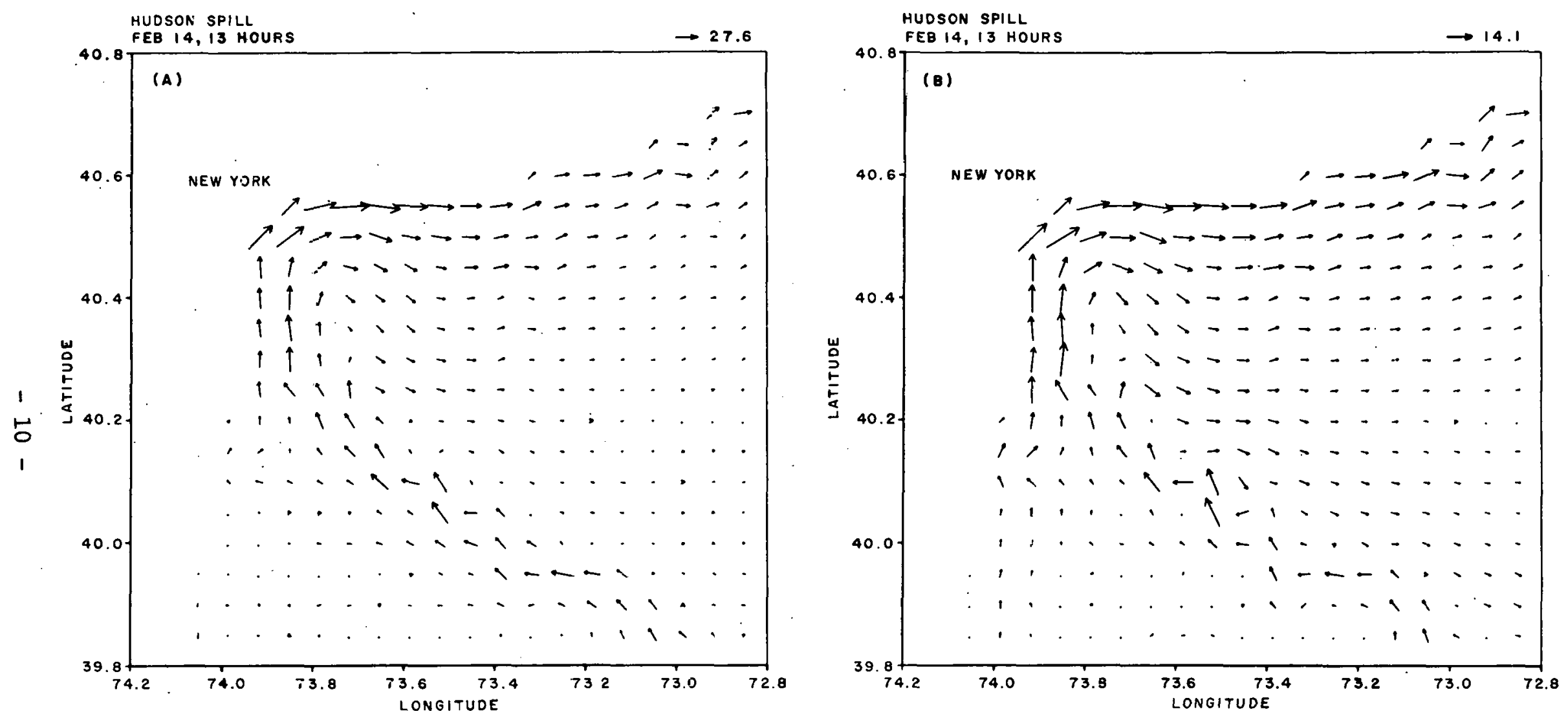

Figure 5. Computed currents using forecast winds (A) and observed rinds (B). The vector length is proportionel to the maximum vector shown at the top right of each figure. The model was driven by observed winds starting on 9

February, ending at 1300 on 13 February with a 24-hour forecast in $(A)$ and observed winds starting on 9 February in (B). The winds used are shown in Figure 4. 
The forecast is illustrated in Figures 6 and 7.011 floating at position 9 on February 11 at 1600 was expected to reach the eastern half of Jones Beach about 0400 on the 13th (the trajectories are marked with a " + " each six hours), whereas there was less threat from the other two positions (Figure 6a). However, by the evening of the $12 \mathrm{th}$, oil at position 3 could reach Rockaway in 6 hours and oil at position 2 could reach Long Beach in 12 hours (Figure $6 \mathrm{~b}$ ). This oil could reach the eastern end of Jones Beach by the end of the forecast period (0400 on February 14). The transport due to the currents only is shown in Figure 7a for the other thræ release positions. The effect of a continuous release is shown in Figure $7 \mathrm{~b}$, where the positions of all particles released from all nine drop points since 1600 February 11 are plotted at 1000 February 13. The particles are mostly bunched along Long and Jones Beaches. The accuracy of the forecast can be assessed by reference to the initial discussion of this section. Basically, it appears that there was less threat from the southern positions than expected and that the oil would not have moved as far east as forecast for the end of the period. Furthermore, the plots for forecast 1 in 1 Figure 4 indicate that the initial beaching would have been about $5 \mathrm{~km}$ west of the forecast. We did not rerun this forecast using the observed winds. This could be done if data is available on the initial conditions of the oil spill, along with beaching observations. It is our understanding that oil was found on Rockaway on Sunday, the 13th.

Four mnre 36=hour forecasts were done for MESA, the last being on Wednesday, the 16th. None of these indicated that there was any hazard to Long Island or New Jersey. The surface trajectories for drop points 1,2 and 3 for each day are shown in Figures 8 and 9 . The trajectories 

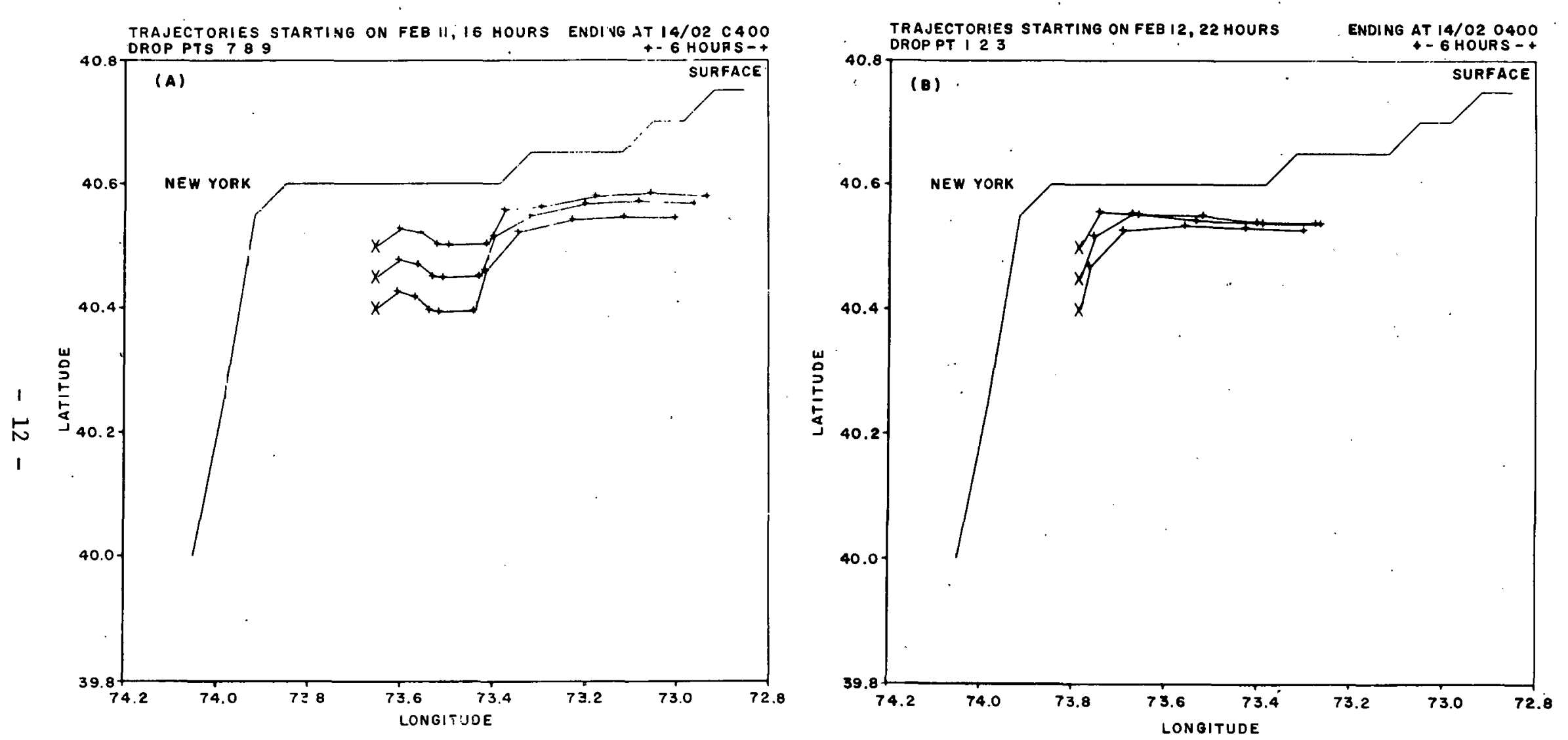

rigure 6. The surface oil trajectory forecast given to MESA en 12 February. The drop points are mapped in Figure 1 . The oil was forecast to reach Long Island by the morning of the 3th, the particular jeach depending upon the initial position oj the oil. The trajectories are marked at 6-hour intervals vith a "+". The starting and ending times are listed at the top of each figure. 

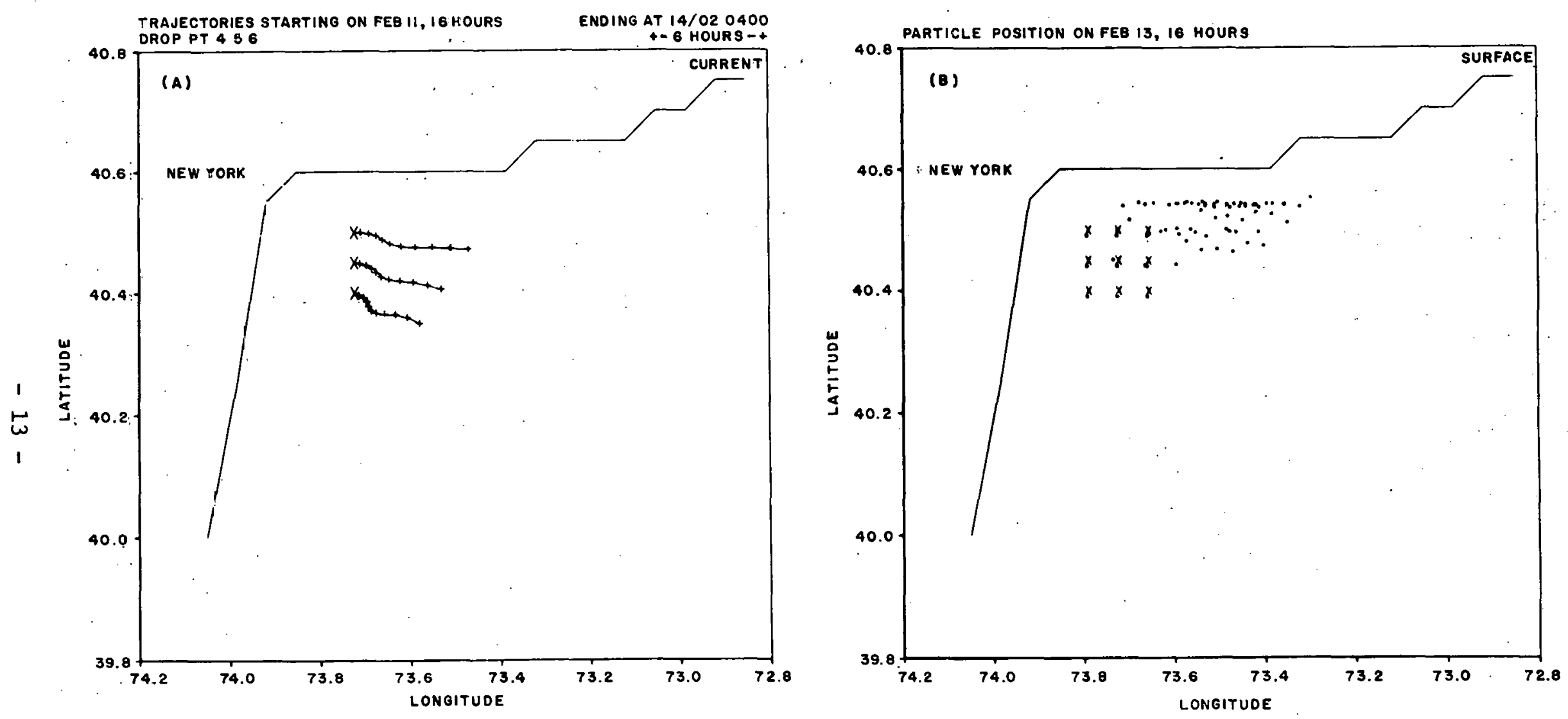

Figure 7. The water column trajectories are plotted at 6-hour intervals $(A)$, where the starting times and positions are labeled at the top. In (B) the positions of all particles re-

leased since 1600 February 11 are plotted, simulating a continuous release from all nine points. 

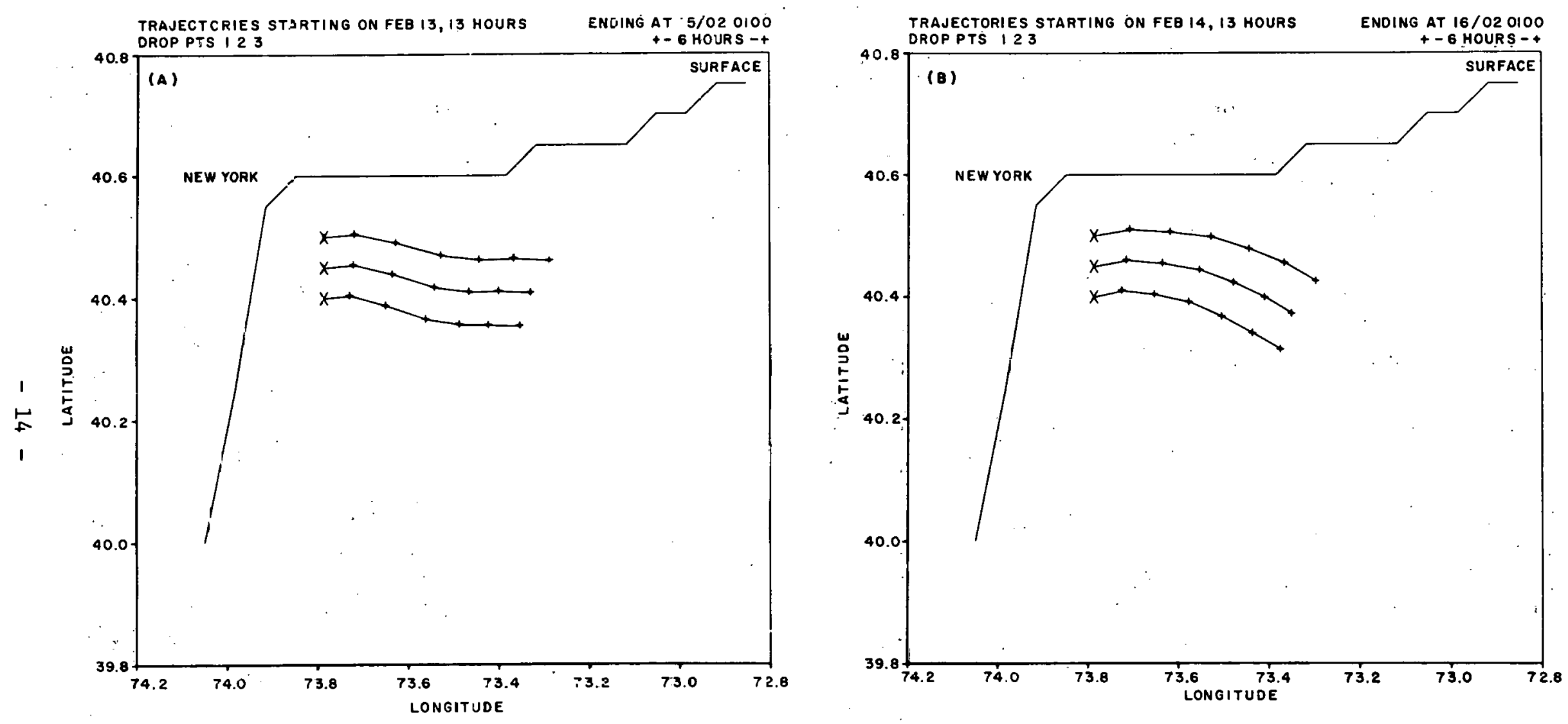

Figure 8. The surfaze slick forecast for February 13 (A) and February 14 B) for trop points 1,2 , and 3 . There is no apparent threa: to Long Island. 

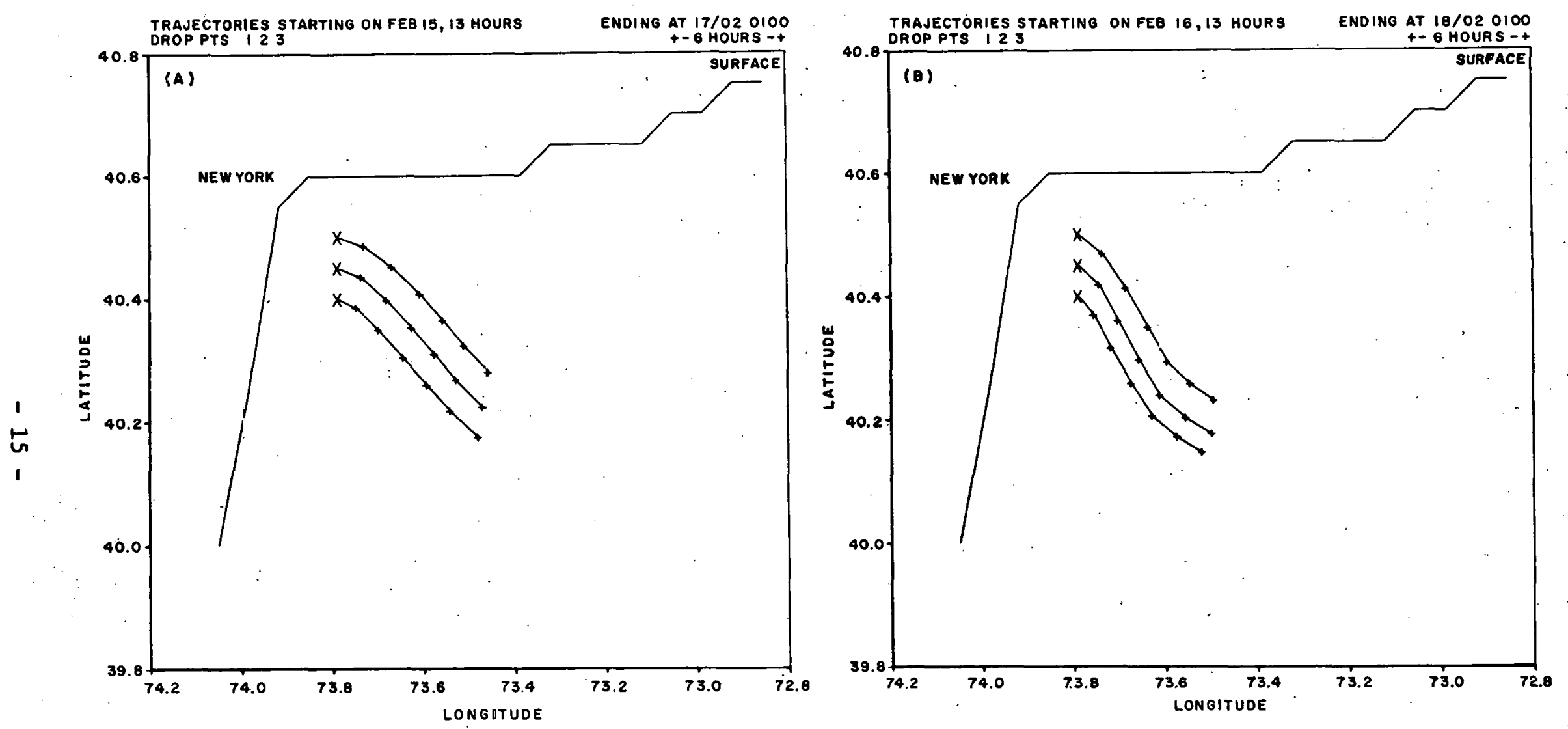

Figure 9.. The surface slick forecast given to MESA on February 15 (A), and 16 (B). As in Fig. 8, there is no threat to Long Island. Since oil was not observed entering the Apex and the wirds were expected to continue favorable, the forecasts were terminated. 
varied from east to southeast. Since no more oil was observed entering the Apex, it seemed that no further runs were warranted.

IV. The Beaching of Oil on February 22

On Tuesday, February 22, oil was found on Rockaway, and possibly also on Long Beach. The details were not clear on the 24 th as to where and when the beaching occurred, or as to whether oil was observed entering the Apex. However, we agreed to run the model using the observed winds for about five days encompassiug the bcaching event, since this was an opportunity to test the forecast procedure independent of any errors in the forecast winds. The complete model results are available on microfiche for comparison with observations as they become available, but here we show a few examples to outline what might have happened.

The wind observations were not available by telephone (because WSFO does not keep them) but Jim Allen of the WSFO in New York mailed them to us on March 3. The winds were the 3-hour Ambrose observations starting at $00 \mathrm{z} 19$ February (for model runup) and ending at 21224 February. The winds are plotted as $3 \%$ of the wiud PVD in Figure llla (the times are EST). The transport of particles in the water column released lium the wistern most drop points at 1300 February 20 is shown in Figure 10b. The trajectorics are marked with a " + " each 6 hours and are going through a clockwise motion. The current's change quite rapidly during this period. For example, a strong eastward flow changes to a strong westward flow in 24 hours on February 23 (Figure 11).

An examination of the computed surface trajectories indicates that material fluating in the $\Delta$ pex prinr to the 21 st would not have beached. 
(A.)

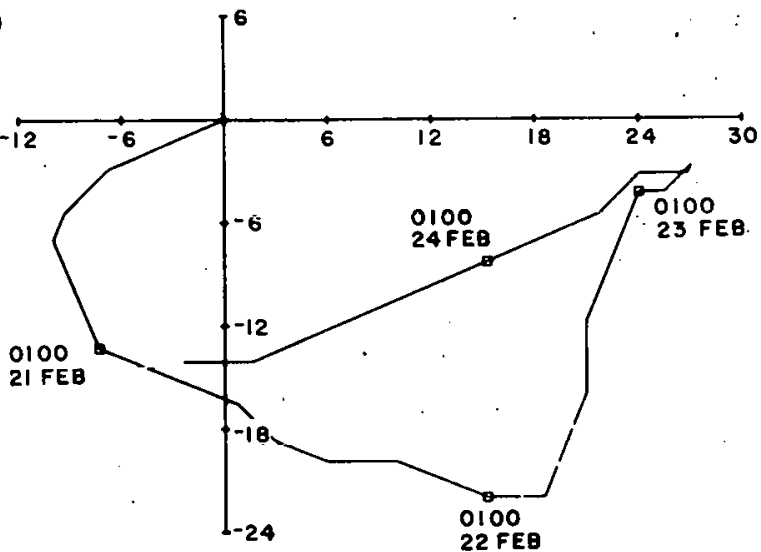

PVD (KM) OF TRANSPORT WIND 20 FEB OTOO-24 FEB 1600

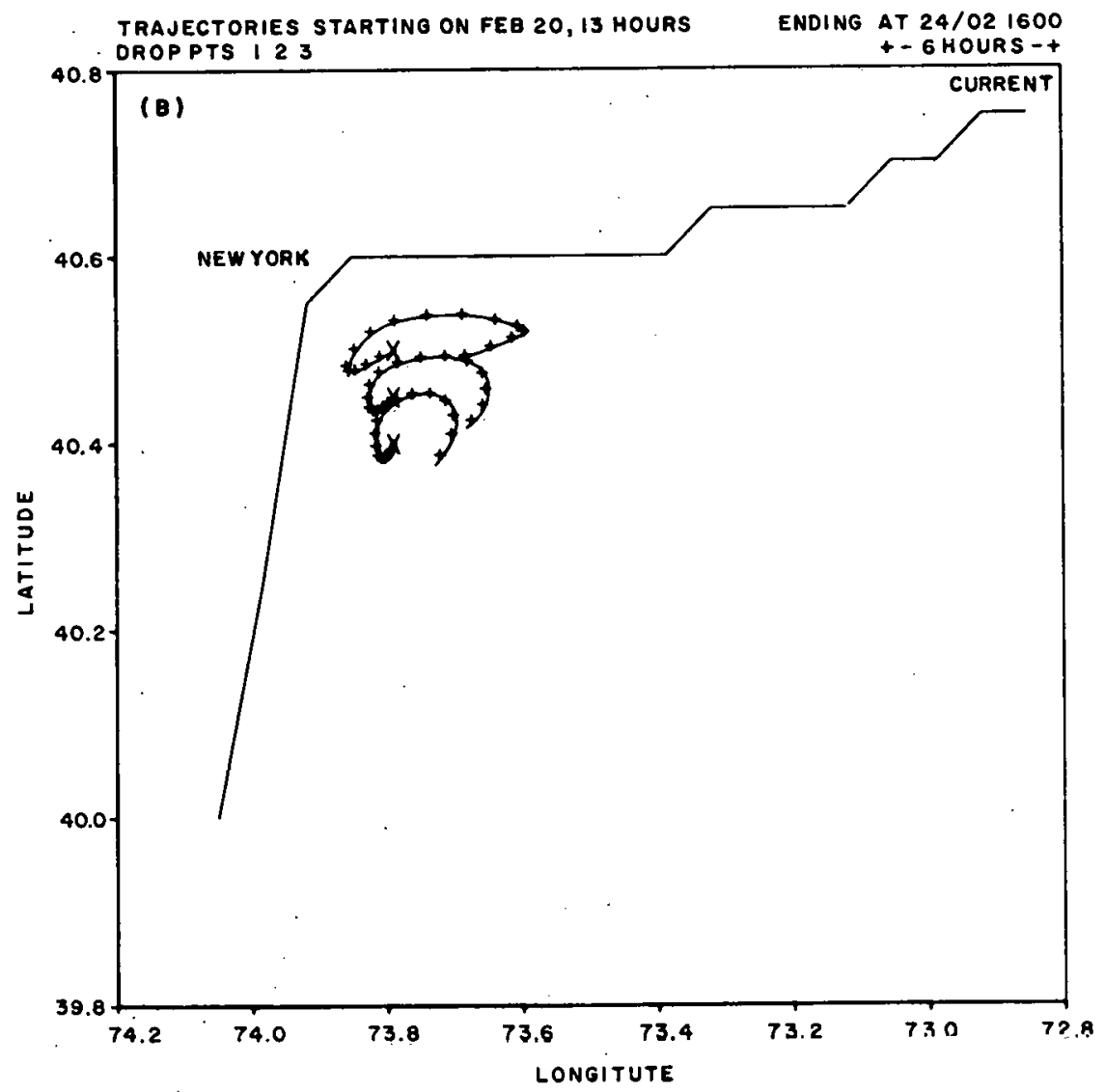

Figure 10. The observed winds used for an analysis of the beaching on February 22 plotted as $3 \%$ of the wind PVD (A). The transport due to the currents only (marked at 6-hour . intervals) are shown in (B). 

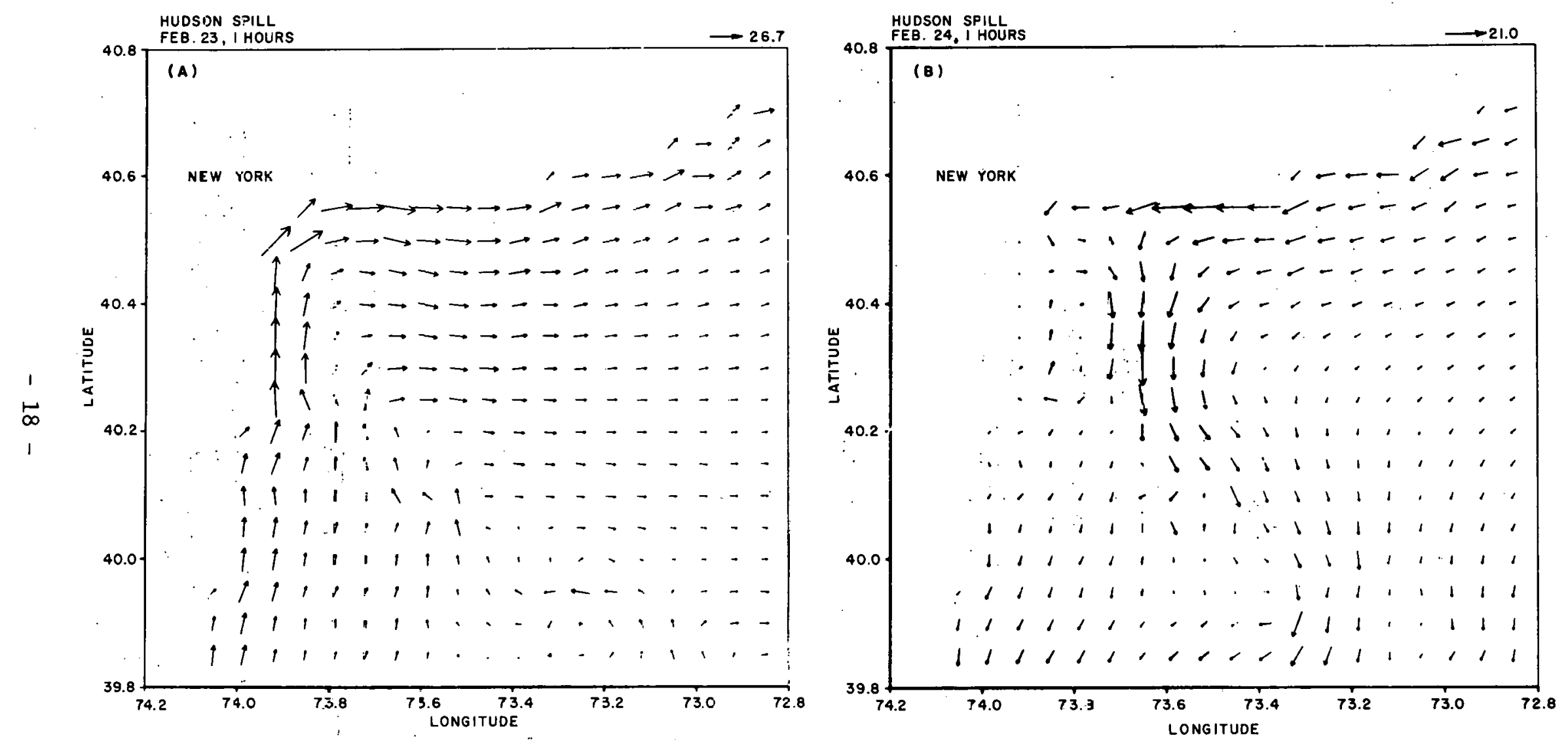

Figure 11. Strong easterly currents in the Apex on February 23 (A) are reflaced by strong westward currents on February 24 (B). No new oil was observed on the beaches after this period. 
Furthermore, oil initially at drop points 2 and 3 at 1300 on February 21 should have washed ashore on Jones Beach on the evening of the 22nd, and oil at point 1 might not have beached at all (Figure 12a). If we consider the same points 12 hours later (Figure 12b), oil should have been washing ashore on Long Beach on the afternoon of February 22. It appears from the model results that oil would have to be near Ambrose tower (drop point 3 ) on the morning of the 22nd in order to beach on Rockaway. If these model results are realistic, they could be used to narrow the seach for observations.

Another way to analyze the event is to treat the problem as a continuous spill from al1 nine points, starting at 0700 EST February 20. In this case, the threatened area extended from Rockaway Beach to Fire Island Inlet on the evening of February 22 (Figure 13a). The particles to the southeast were all released prior to February 21 . It is clear that there is no threat to Long Island after 23 February (Figure 13b), but that some later releases could be heading down the New Jersey shoreline. V. The Microfiche Plots

The microfiche appended to this report contain all the plots made for each forecast, the plots used for the analysis of the oil beaching on February 22, and the winds used for each forecast. The five fiche labeled SPL-12, SPL-13, SPL-14, SPL-15, and SPL-16 are the forecasts given to MESA on February 12 through 16, respectively. The format (starting at the upper left and going down each column) is:

1) A vector plot of the computed currents for the Bight Apex starting at the beginning of each forecast period and plotted 

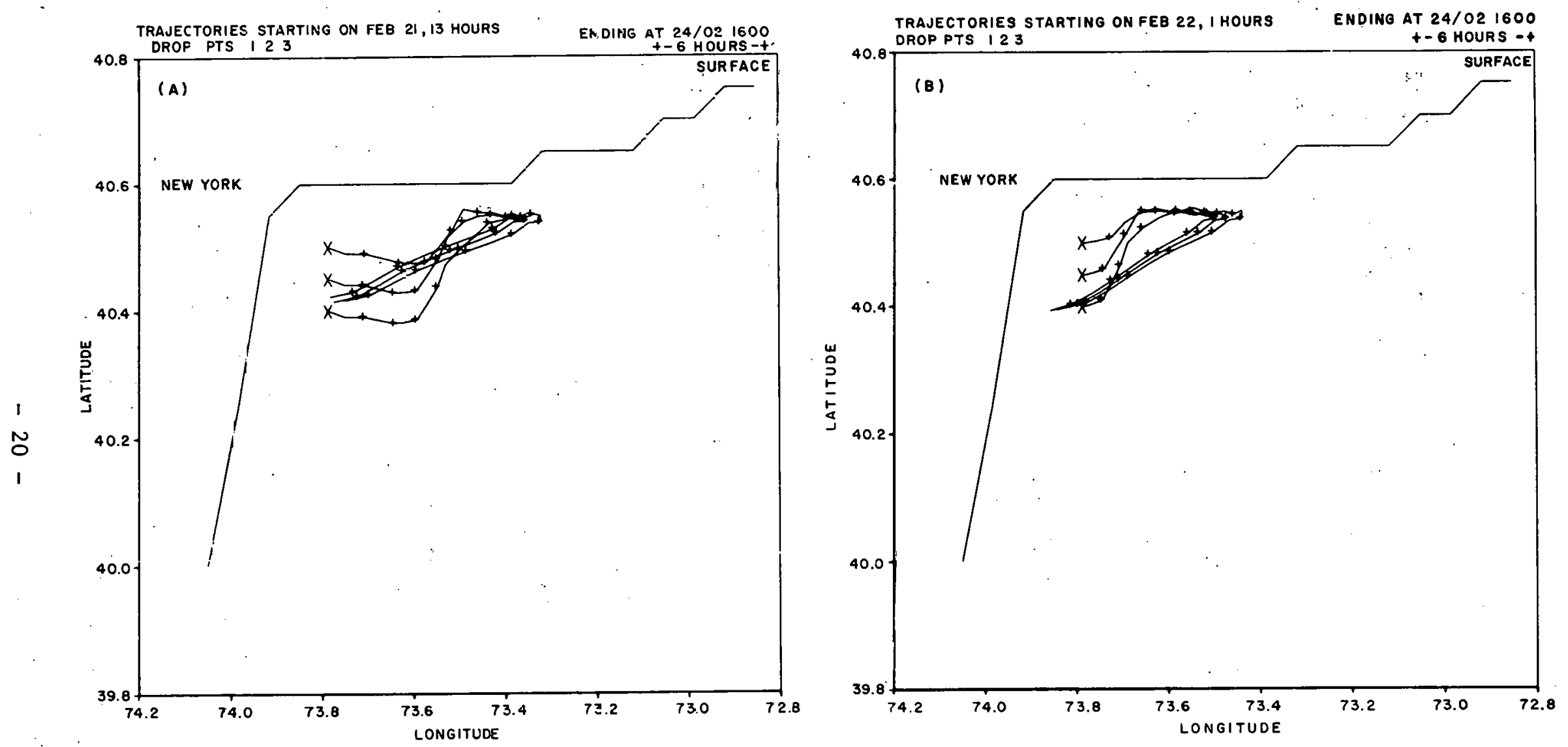

Figure 12. Comsuted surface trajectories starting at 1300

February $2 \Xi$ (A) and 0100 February 22 (B). In (A) the threat is to Jones Beaci and in (B) to Long Beach. From trajectories like these we concluce that the beaching on the 22nd probably came from o:l floating near Ambrose on the morning of Februar; 22 . 

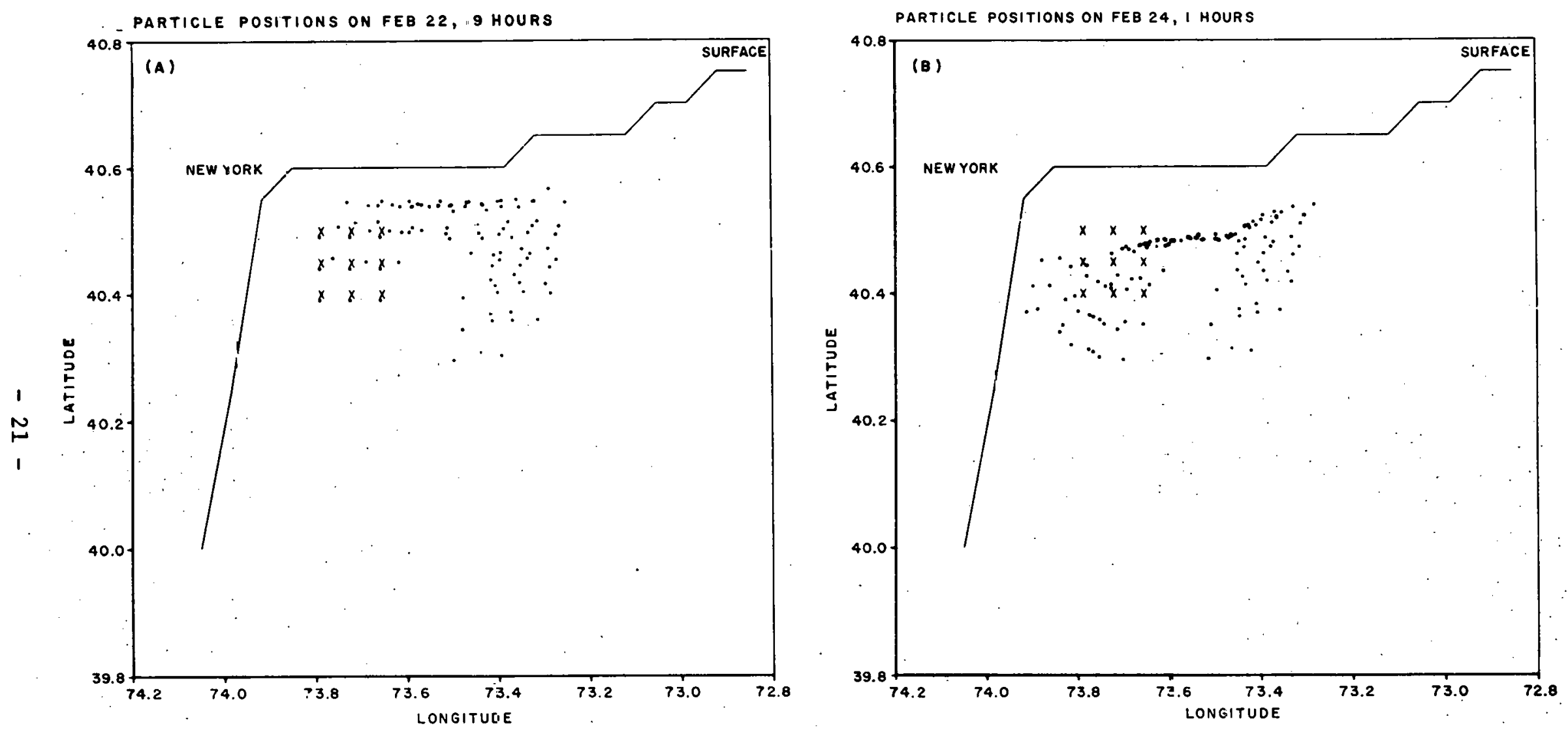

Figure 13. The positions of all particles released from 0700 February 20. There is a clear threat to Long Island in (A) but not in (B). 
each six hours until the end of the period. The vectors are proportional to the maximum shown in the upper right corner $\left(\mathrm{cm} \mathrm{sec}^{-1}\right.$ ) (see Figure 5);

2) A map showing the latitude-longitude key to the drop points (see Figure 1);

3) Surface trajectories, with the starting and ending times listed at the top. The first plot in this series shows trajectories from points $1,2,3$, then points $4,5,6$ and then points $7,8,9$. The trajectories are makred with a "+" each six hours. The plots continue in this group of three, with a starting time each six hours until the end of the forecast period (see Figure 6);

4) The same format is used for the water column trajectories. This series is labeled "CURRENT" in the upper right corner (see Figure 7a);

5) The particle surface positions are plotted in a series, six hours apart, representing a concinuous relcace from fli nine release points (see Figure $7 b$ );

6) The same format is used for the particle positions in the water column.

7) A PVD of $3 \%$ of the wind eranspusL. Exccpt for SPT -12 the PVD's are incorrect (see Figure 4).

The fiche labeled SPL-20 contains the plots of the beaching on fiebruary 22 . The format is the same as above and the wind PVD is correct. The fiche labeled SPL-PVD contains the winds used for cach forerast. The last plot is the observed winds. These are al1 $3 \%$ of the wind transport. 